the action of oxygen on clean germanium surfaces and a theoretical discussion. The outcome of some of the work described could be of overwhelming importance in improving the initial performance, the consistency and the reliability of transistors.

There are some gaps in the subject as presented, and some contrasts in presentation; but generally the book is very readable and is recommended to everyone studying the physics of semiconductors or the technology of transistors or somiconductor diodes. J. R. TILLMAN

Quantitative Chemical Analysis

By Prof. Robert B. Fischer. Pp. xii +401. (Philadelphia and London: W. B. Saunders Company, 1956.) 38s. $6 d$.

7 HE author, a professor in the University of Indiana, is acutely aware that many a student whom he instructs in analysis will never use it in his career, and that those who become industrial chemists are more likely to meet a kind of analysisinstrumental-other than that learned at the university. Accordingly, Prof. R. Fischer has framed his course to meet this condition of things. His guiding principle seems to be to inculcate scientific thinking and so make the study and practice of analysis a training in research. Of the book's five parts the first consists of a well-planned and well-written introduction. Parts 2 and 3 deal with a selection of standard gravimetric and volumetric methods such as are usually found in first-year university courses. Part 4 is intended to be an introduction to instrumental analysis. It contains a description of optical and electric methods, but gives laboratory procedures for simple colorimetry and electrodeposition only. Part 5 consists of tables, including one of five-place logarithms. Ninety illustrations, including highly magnified electron micrographs of familiar precipitatos, add to the interest of the subject-matter.

Throughout the book the treatment is thorough. Several of the chapters, such as the one on precipitation, and that dealing with analytical data, are, as it were, self-contained scholarly reviews of the subjects in question. Before any determination is undertaken the student is trained to seek out and study the fundamental chemistry involved, and to select the most appropriate techniques. Serious students mastering this book will get a good grounding in the theory and practice of quantitative analysis and will not find it a dull subject.

G. FowLes

\section{Volumetric Analysis}

By G. Fowles. Revised and enlarged edition. Pp. xiii + 235. (London: G. Bell and Sons, Ltd., 1957.) 12s. $6 d$. net.

$\mathrm{T}$ this edition the framework of the original text 1 has not been altered, apart from the occasional rewriting of explanatory matter, such as that on $p H$ and redox indicators. Two new chapters have been added, one on 'complexing processes' and the other on ceric sulphate as an oxidizing agent. In addition, forty-six numerical problems with answers have been added, together with a table of logarithms. The simple account of 'complexing processes' is very satisfactory, apart from the misleading statement that a bromide will not give a precipitate with the solution obtained by dissolving silver oxide in aqueous ammonia. Many teachers will welcome the clear exposition of Schwarzenbach's method for the determination of the hardness of water by the use of the sodium salt of ethylenediamine tetracetic acid-- the name is much more frightening than the formula or the method of using it. The use of standard solutions of ceric sulphate is discussed and illustrated by a number of examples. As the author rightly points out, cerium is not a rare element, and ceric sulphate possesses many advantages over potassium permanganate as a reagent in volumetric analysis. The first edition of this book provided for an obvious need-it was reprinted five times-so that this volume with its useful additions should have a favourable reception.

A. C. CAVEli

Thought, Life and Time as Reflected in Science and Poetry

By Dr. H. C. Wood. (Tenth Arthur Stanley Edding. ton Memorial Lecture, 19 February, 1957.) Pp. vi + 58. (Cambridge: At the University Press, 1957.) 4s. $6 d$. net.

THIS, the tenth Eddington Memorial Lecture, is a worthy member of the series, and of note in that the author approaches his difficult task along the paths of history and theology. This route is, in the event, not so roundabout as it might appear. Eddington himself regarded natural science as a means of reaching one of the frontiers of human knowledge, beyond which other concepts, poetical, metaphysical or religious, had to take charge if the totality of our apprehension was to be achieved. One result of this was that Eddington wrote such beautiful prose (a lesson indeed to many a scientist) that occasionally he invited criticism for ambiguity. But the gain was greater than the loss : the resthetic quality of his analysis was a direct challenge to the near-identity of truth and beauty.

For the rest, it seems unlikely that mankind has been vouchsafed something at least akin to a spark of the Divine if his desire to know ultimate truth is to remain for ever unsatisfied. We have yet to be convinced that a robot can be constructed to which it matters that, if it thinks, its thoughts are true.

Finally, the university must never lose or take lightly its emphasis upon intellectual imagination, and all that such a privilege implies. Following Eddington's footprints on the sands of time, it should be secure. F. I. G. Rawtins

Seven Pond Creatures. Seven Birds. Seven Trees. Seven Animals

15 pp. each. By Edna Johnson. (Oxford: Basil Blackwell, 1957.) 2s, each.

/ANY writers have attempted to deepen the 1 interest of young children in living creatures. In a well-known series Enid Blyton used her imaginative gifts to prepare delightful fairy-like stories based on authenticated fact ; the series was wholly successful. Other writers have prepared factually accurate accounts which have been less successful because they took insufficient note of the romantic quality of the child-mind. In this series Edna Johnson uses brightly coloured illustrations by Anyon Cook to attract attention and then adds to the interest by text which has been meticulously prepared and which has all the appeal of simple blank verse. It should commend itself to most young children. The text is precise, accurate, sparing of words and supplemented both by homely black-and-white drawings and by photographs from well-known bird photographers. The drawings are worthy of the coloured illustrations and the text; some of the photographs are badly repro. duced and do not add to attraction or understanding. 